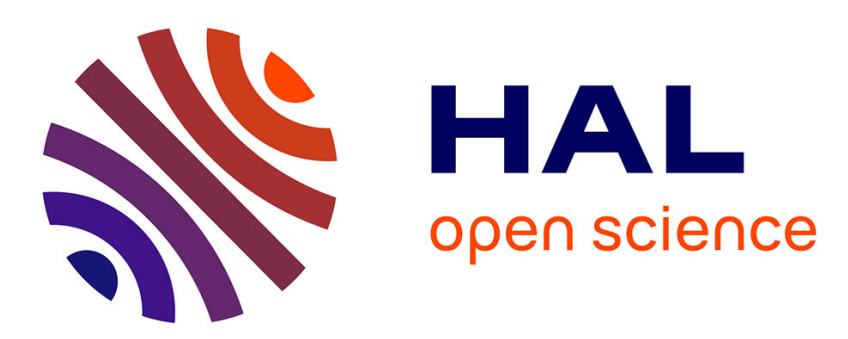

\title{
Investigations of the effect of strain path changes on forming limit curves using an in-plane biaxial tensile test \\ Lionel Leotoing, Dominique Guines
}

\section{To cite this version:}

Lionel Leotoing, Dominique Guines. Investigations of the effect of strain path changes on forming limit curves using an in-plane biaxial tensile test. International Journal of Mechanical Sciences, 2015, 99, pp.21-28. 10.1016/j.ijmecsci.2015.05.007 . hal-01157311

\section{HAL Id: hal-01157311 https://hal.science/hal-01157311}

Submitted on 27 May 2015

HAL is a multi-disciplinary open access archive for the deposit and dissemination of scientific research documents, whether they are published or not. The documents may come from teaching and research institutions in France or abroad, or from public or private research centers.
L'archive ouverte pluridisciplinaire HAL, est destinée au dépôt et à la diffusion de documents scientifiques de niveau recherche, publiés ou non, émanant des établissements d'enseignement et de recherche français ou étrangers, des laboratoires publics ou privés. 


\title{
Investigations of the effect of strain path changes on forming limit curves using an in-plane biaxial tensile test
}

\author{
Lionel Leotoing ${ }^{1}$, Dominique Guines \\ Université Européenne de Bretagne, France, INSA-LGCGM-EA 3913 \\ 20 Av. des Buttes de Coësmes, CS70839, 35708 Rennes Cedex 7, France
}

\begin{abstract}
Optimization of sheet metal forming processes requires a very good knowledge of material forming ability, more especially for aluminum alloys which generally exhibit a poor formability at ambient temperature. During the forming of industrial parts, very complex strain paths are usually observed and can affect the formability of the sheet. In this work, in order to investigate strain path effects on formability, an innovative one-step procedure is proposed to control the strain path changes with a single test, without unloading. The test is based on the use of a cruciform shape loaded with a planar biaxial tensile device. Strain path is controlled by the displacements in the two main directions of the cruciform specimen. For a given non-linear strain path type, experimental forming limit points are greatly influenced by the level of prestrain which can either improve or reduce formability. The same tendency is observed when using a predictive tool based on a finite element model of the same cruciform shape and a rather good correlation is observed between experimental and numerical results.
\end{abstract}

\footnotetext{
${ }^{1}$ Corresponding author, lionel.leotoing@insa-rennes.fr, +33(0) 223238376
} 
Keywords: Cruciform specimen; strain path changes; Forming Limit Curve (FLC); in-plane biaxial tensile test

\section{Introduction}

In sheet metal forming processes, the evaluation of material formability permits to quantify the forming limits of sheets. Many operating environment factors, like temperature, strain rate or strain path can affect this formability. The optimization of forming processes with predictive tools needs a very good knowledge of material formability in order to fully exploit the forming ability of the material. Thus, characterizing the formability of metal sheets for the actual operating conditions is essential to predict the success of complex part forming.

The very classical tool to quantify the formability of metallic sheet is the Forming Limit Diagram (FLD). A FLD is a strain diagram built with the in-plane principal strains in which a Forming Limit Curve (FLC) can distinguish between safe and necked points. The determination of Forming Limit Curves has always been the subject of extensive experimental, analytical or numerical works. Experimentally, two conventional tests have been defined : the out-of-plane stretching (e.g. Nakajima test) and the in-plane stretching (e.g. Marciniak test). With these tests, a high number of specimens with various geometrical specifications is required to plot a whole FLC, from uniaxial tension to equibiaxial tension path. Moreover, only very simplistic linear strain paths are encountered and investigations of effects of strain path changes remain impossible for the same test. Many predictive tools exist for FLCs, they are mainly based on the Marciniak and Kuczynski model (M-K model). It is a widely used analytical tool in which the onset of necking is 
caused by a geometrical imperfection. The definition of the initial geometrical imperfection factor remains uncertain and the value can be adjusted by making the best fit with experimental results or by performing a microstructural analysis of the metallic sheet [1]. Moreover, the choice of an appropriate constitutive model for the sheet material is a key to obtaining the practical prediction of FLCs.

Using a cross specimen to characterize and predict forming limit curves can be an interesting alternative to overcome the major drawbacks of the conventional methods [2]. The test is frictionless and one of the main advantages of this shape is that the strain path during the test and at the onset of necking can be directly controlled by the motion of four independent actuators, independently on the specimen geometry. A unique geometry is then sufficient to cover the whole forming limit diagram and to investigate the influence of strain path by applying linear or non-linear loadings. The main drawback of this test is related to the design of the cross specimen. Very recently, the International Standard ISO16842 [3] has been proposed. This standard specifies the testing method for measuring the biaxial stress-strain curves of sheet metals subject to biaxial tension at an arbitrary stress ratio. The test piece is made of a flat sheet metal with a uniform thickness. The measured biaxial stress-strain curves are used to determine contours of plastic work of the sheet samples. This standard is based on the research work of Kuwabara et al. [4], stresses are calculated by assuming an equivalent cross section. Unfortunately, this shape cannot be used for formability studies since the strain level measured in the central zone is very low, necking systematically appears in the arms. Many designs are available in litera- 
ture to identify initial yield surface [5] or hardening behaviours [6] but the determination of forming limit curves with cross specimens has received little attention. $\mathrm{Yu}$ et al. [7] proposed a cross specimen with a chamfer on the arms and the central region to reach limit states. The interest of the cruciform shape was clearly demonstrated but no forming limit curves have been performed with this specimen. First experimental forming limit curves have been presented by present authors [8] with a dedicated cross specimen design. Numerically, the use of the finite element method to model the cross shape allows the implementation of complex mechanical behaviors in order to evaluate the influence of operating conditions like temperature or strain rate, in the range that covers the whole process. Moreover, due to the specimen shape, the calibrating step of the initial geometrical imperfection factor which is essential for M-K model becomes unnecessary.

Many authors have demonstrated that non-linear loadings, frequently encountered in industrial processes, have a great influence on level and shape of FLCs [9]. In literature, most of the studies are analytical and based on the use of the M-K model. Yoshida et al. [10] have studied forming limits with two types of combined loading : a two linear stress paths in which unloading is included between the first and second loadings, a loading in which the strain path is abruptly changed without unloading. They have shown that forming limit curves in strain space depend strongly on the strain path while forming limit stresses are only affected by the second type of loading. An interesting study was proposed by Kuroda and Tvergaard [11] to show dependence on whether or not the load on the sheet is removed between two load steps on a non-proportional strain path. Based on the M-K model, this 
theoretical analysis showed that very unstable behaviors can be observed for two load steps without unloading. For specific strain path cases, jumps of forming limit curve were observed and explained by a quick change of stress point along the yield surface. Hiwatashi et al. [12] have introduced an anisotropic model based on texture and dislocation structure to improve predictions of some experimental tendencies. An anisotropic damage model was extended by Chow et al. [13] to improve the predictions of AA6111 FLCs. For the specific case of aluminium alloys, the studies are mainly focused on 6000 series, prestrain in biaxial tension generally decreases the formability if followed by plane strain or biaxial tension but prestrain in uniaxial tension, along the rolling direction, increases the forming limits if followed by biaxial tension. If principal strains are rotated after prestraining, forming limits systematically decrease. A stress-based forming limit concept was proposed in the early 80s [14] which seems to be independent on strain path changes. This concept was adopted by many authors ([15], [16]) even if a stress state cannot be measured experimentally. Experimental forming limit stress diagrams are indirectly achieved by a good description of the plastic behaviour of the material (yield criterion and hardening law) [17].

Very recently, new original theoretical works have been published on this very open issue, like the study on the effect of a double strain path change [18] on formability of AA6016 or the study of the effect of normal stress on the formability of sheet metals under non-proportional loading [19]. An alternative methodology to the use of the M-K model has been proposed by Uppaluri et al. [20] which work focussed on the developing of a simple analytical tool based on the modified maximum force criterion (MMFC). The 
predictions of the proposed model have been compared with experimental results and have been found to be in good agreement with each other.

Experimentally, due to the complexity of the procedure, very few experimental data exist about effect of strain path changes. In the 90s, a very early experimental work is the one of Graf and Hosford [21] on aluminum alloy 6111 in which FLCs of specimens prestrained to several levels in uniaxial, plane strain and biaxial tension, parallel and perpendicular to the rolling direction have been determined. These experimental data have been extensively used as reference experimental data in many research works ([20], [13], $[22])$. It is impossible to control strain path changes with the conventional tests for FLC characterization and classically a two-step procedure is applied. Prestrains are generally realized by oversized tensile tests (uniaxial or plane strain prestrains) and oversized Marciniak or bulge tests (biaxial prestrain). Afterwards, standard Marciniak or Nakajima tests can be performed on the prestrain sheets. This two-step procedure was also used by Butuc et al. [17] to calculate stress-based forming limits from experimental strain data and more recently by Volk et al. [23] to plot experimental FLCs with six prestrains (from uniaxial to equibiaxial). This very time consuming procedure requires several experimental devices and the measure of the strain path is not continuous between the two steps. In addition, only simplistic prestrains can be applied which makes impossible the study of formability under multiple strain path changes. Finally, in actual forming processes, curved loading path are observed without any unloading and if the loading procedure really influences the forming limits of the material, the classical two-steps procedure with unloading seems to be inappropriate. 
Then, the present study focuses on the potential of the in-plane biaxial tensile test to study the effects of strain path changes on formability with a one-step procedure, without unloading. After some details about the cruciform shape design and the choice of the criterion to detect the onset of necking, experimental results are presented for several levels of prestrain in uniaxial tension. Afterwards, a finite element model of the cruciform shape is used to predict the influence of strain path changes on formability and a comparison is carried out between experimental and predictive results for two elastoplastic behaviours.

\section{Experimental procedure and results}

\subsection{Cruciform shape design and strain paths}

Many cruciform specimens have been already designed to characterize the mechanical behaviour of materials subjected to biaxial loadings [24] but no standard design still exists. A dedicated cruciform shape must be designed in order to observe the onset of necking in the central zone of the specimen. This condition permits a direct control of the strain path of the necking zone thanks to the control of the displacements of four independent actuators acting on the four arms of the specimen. From finite element simulations, different geometries have been investigated. The more effective and the more promising specimen shape (Fig. 1) has been optimized and already presented by the present authors [8]. To concentrate strains in the central zone, strain localisation at the junction of two arms is reduced by a radius ( $R 8$ in Fig. 1) and by longitudinal slots (2.2 $\mathrm{mm}$ width) which decrease the transversal stiffness of the arms. Lastly, a progressive thickness reduction in the central 
zone is adopted to precisely force the onset of necking and rupture at the center of the specimen. The central region of the specimen is fabricated by using a digital numerical turning-lathe, with a precision of $0.02 \mathrm{~mm}$ for the central thickness.

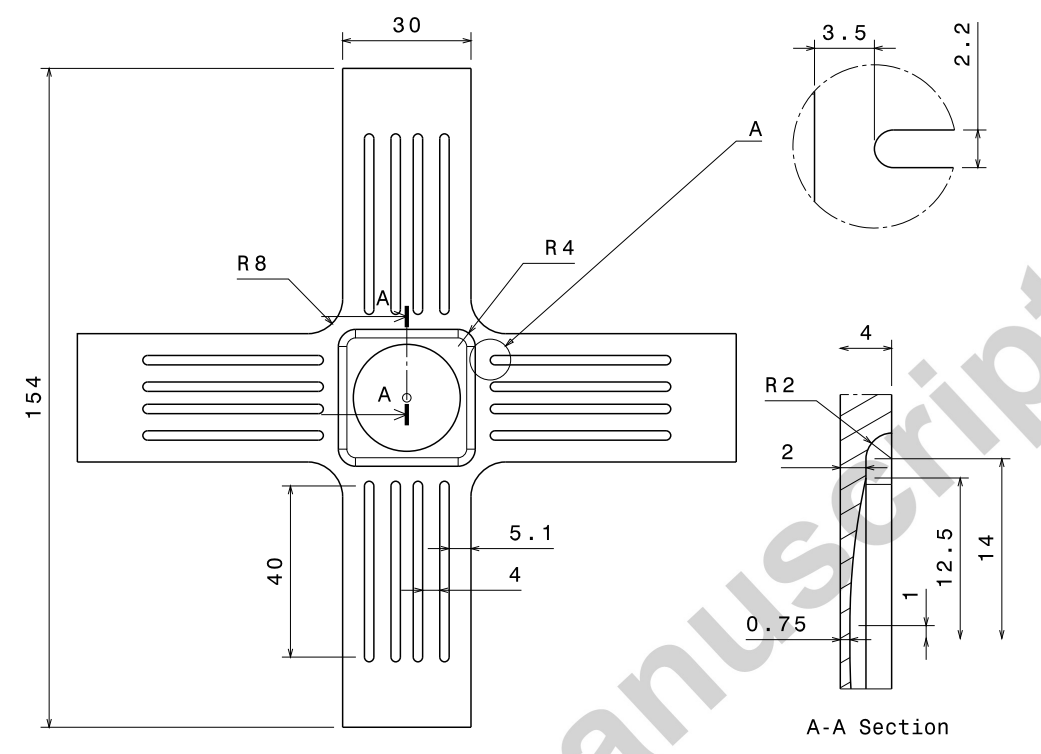

Figure 1: Optimized cruciform shape [8].

For this specific geometry, as illustrated by figure 2, the thickness reduction at the center of the specimen permits to reach an equibiaxial deformation mode when identical speeds are set on the two perpendicular axes of the specimen $(S 1=S 2)$ and a quasi-uniaxial deformation mode when speeds are only set on two opposite arms $(S 1)$. For this last case, the two other arms are free.

The in-plane strains on the surface of the specimen are measured thanks to a digital image correlation (DIC) technique associated with a high resolution camera. The strain path at the central point of the specimen is directly 


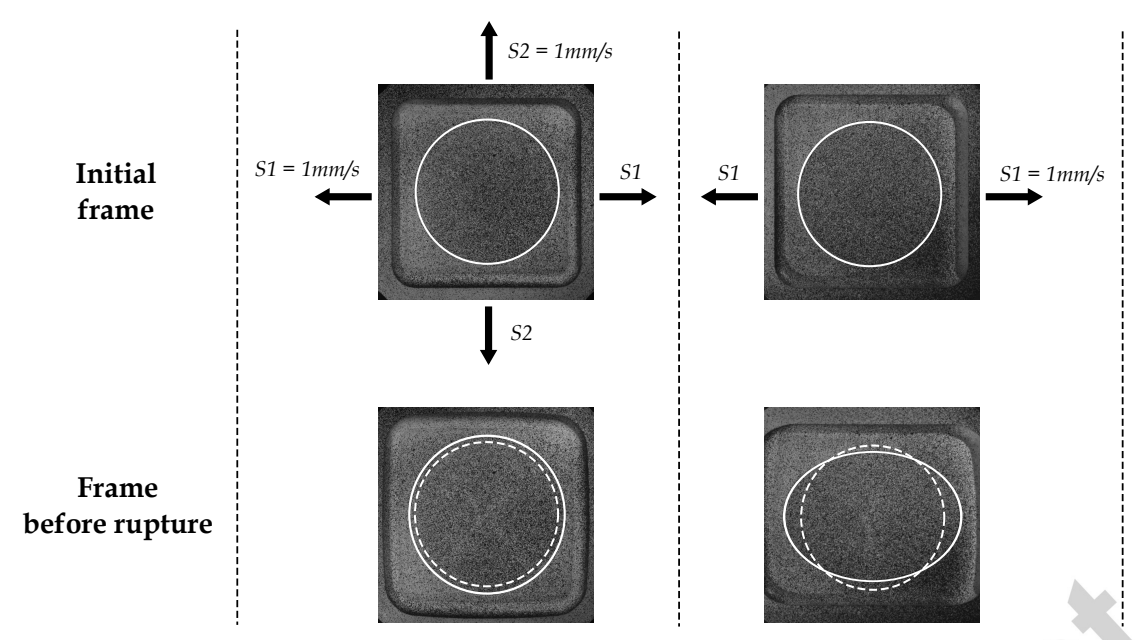

Figure 2: Shape deformation for equibiaxial $(S 1=S 2=1 \mathrm{~mm} / \mathrm{s})$ and uniaxial $(S 1=$ $1 \mathrm{~mm} / \mathrm{s}$ and $S 2$ is free) conditions.

linked to the velocity ratio of actuators. The strain paths for the two specific boundary conditions of figure 2 are shown in figure 3. For a constant speed ratio, the strain path is quasi-linear as it is usually observed in conventional tests of formability (Marciniak or Nakajima). By changing the velocity ratio of actuators, all the strain states between uniaxial and equibiaxial can be observed. Moreover, changes of the velocity ratio during the test induce changes of the strain path in the necking zone and then can permit the study of their effects without any restriction about the type of non-linear path.

To test the specimens, a servo-hydraulic testing machine provided with four independent dynamic actuators is used [8]. The center point of the specimen is always maintained stationary during the test thanks to an efficient servo-hydraulic control. For each actuator, the loading capacity is $50 \mathrm{KN}$ and the maximum velocity can reach up $2 \mathrm{~m} / \mathrm{s}$. 


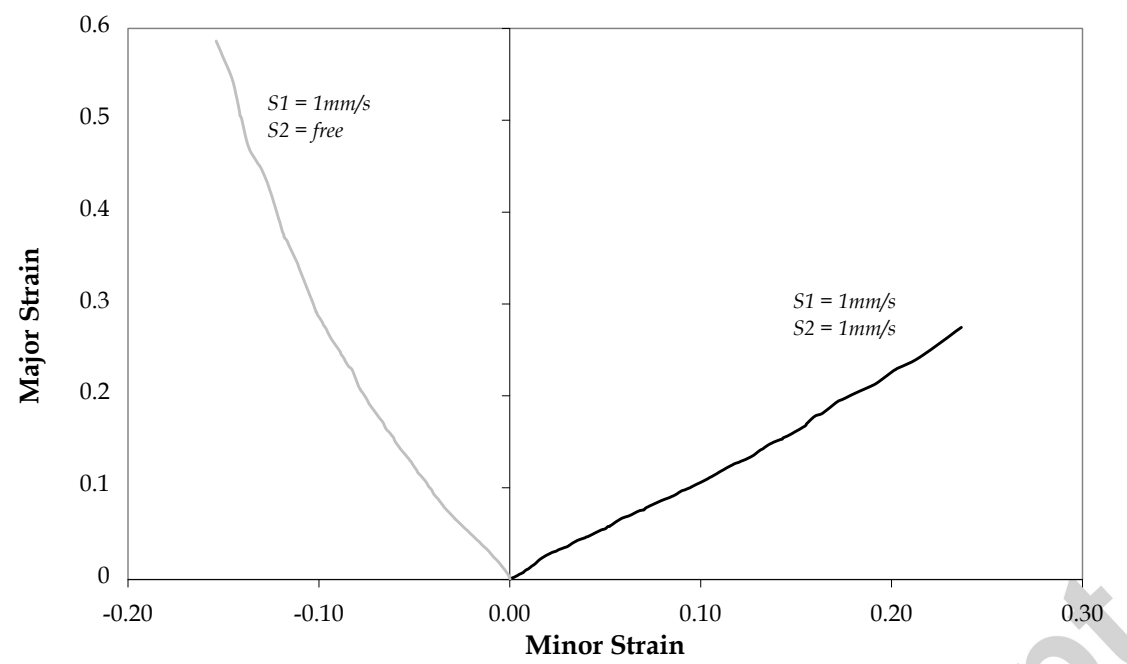

Figure 3: Strain paths for equibiaxial $(S 1=S 2=1 \mathrm{~mm} / \mathrm{s})$ and uniaxial $(S 1=1 \mathrm{~mm} / \mathrm{s}$ and $S 2$ is free) conditions.

\subsection{Method to detect the onset of necking}

The main difficulty in characterizing experimental forming limit curves lies in the choice of an appropriate criterion to detect the onset of necking. The international standard ISO 12004-2 can be applied using either the Nakajima or the Marciniak procedure. In the standard, the limit strains that can be imposed on the material are determined through interpolation, using a position-dependent method. Due to its simplicity, a critical ratio method was applied in previous author works ([2], [8]) to determine forming limit points. Indeed, when necking occurs in a zone, a sharp change of strain is observed due to the onset of a plastic instability. Outside the necking zone, the level of strains remains stable and constant. When the equivalent strain increment ratio between a point located inside the necking zone (zone 1 in Fig. 4(b)) and outside the necking zone (zone 2 in Fig. 4(b)) reaches a crit- 
ical value, the corresponding major and minor strains in zone 1 define one point of the FLC. The main advantage of these two methods is that they are only based on the analysis of strain fields.

A time-dependent method is under development and will be standardized soon. In literature, some time-dependent analysis methods have been proposed, they are mainly based on the follow-up of the strain acceleration ([25], [26]). Strains are not directly measured but are obtained through the space derivate of the displacement fields. Then two additional time derivations are performed to compute strain acceleration. Due to the noise in the fullfield measurement, it is very difficult to get a strain acceleration evolution easy to exploit. This last point will be illustrated hereafter by comparing the results from the three methods : position-dependent, critical ratio and time-dependent methods.

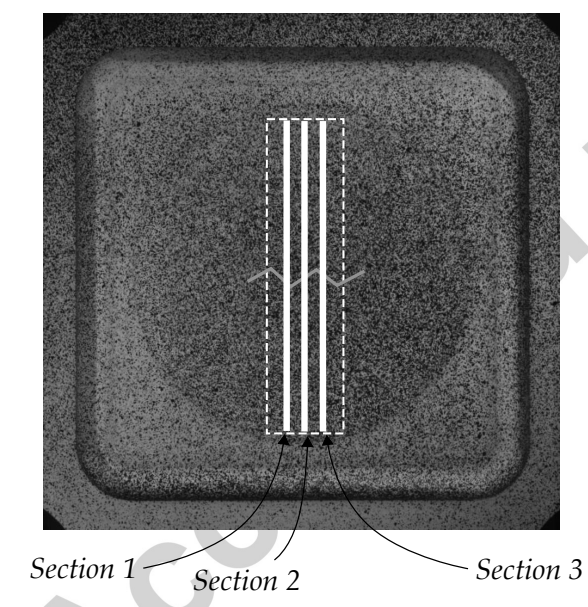

(a) Positioning of the three cross sections

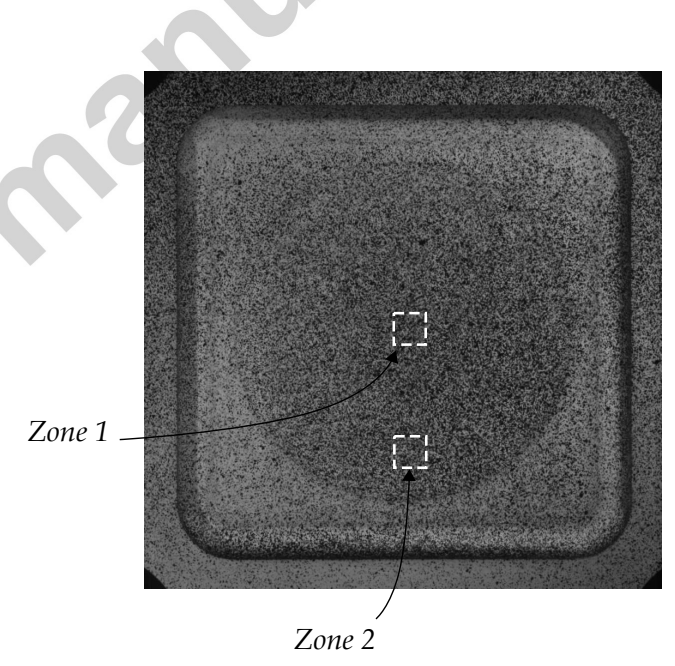

(b) Positioning of the reference zones

Figure 4: Zones of interest of position-dependent and critical ratio methods to detect the onset of necking. 
In order to fulfill the standard requirements concerning the use of a position-dependent method, a modified 'position-dependent' criterion is adopted in the experimental work of the present study to determine the FLCs. As detailed in the standard, on both sides of a necked but not cracked specimen, a second order inverse polynomial function is fitted (Fig. 5) on the major strain profiles $\left(\varepsilon_{11}\right)$ along three sections perpendicular to the crack (1,2 and 3 on figure 4(a)). The maximum value of the fitted curve is used to determine the limit major strain $\left(\varepsilon_{11}^{\text {limit }}\right)$ at the onset of necking. Different from the standard, the limit minor strain value $\left(\varepsilon_{22}^{\text {limit }}\right)$ is directly calculated from the measured strain path $\beta_{\text {exp }}$ through the expression $\varepsilon_{22}^{\text {limit }}=\beta_{\text {exp }} \varepsilon_{11}^{\text {limit }}$. This method limits data scatter on the FLC especially near the plane strain condition (low minor strain values).

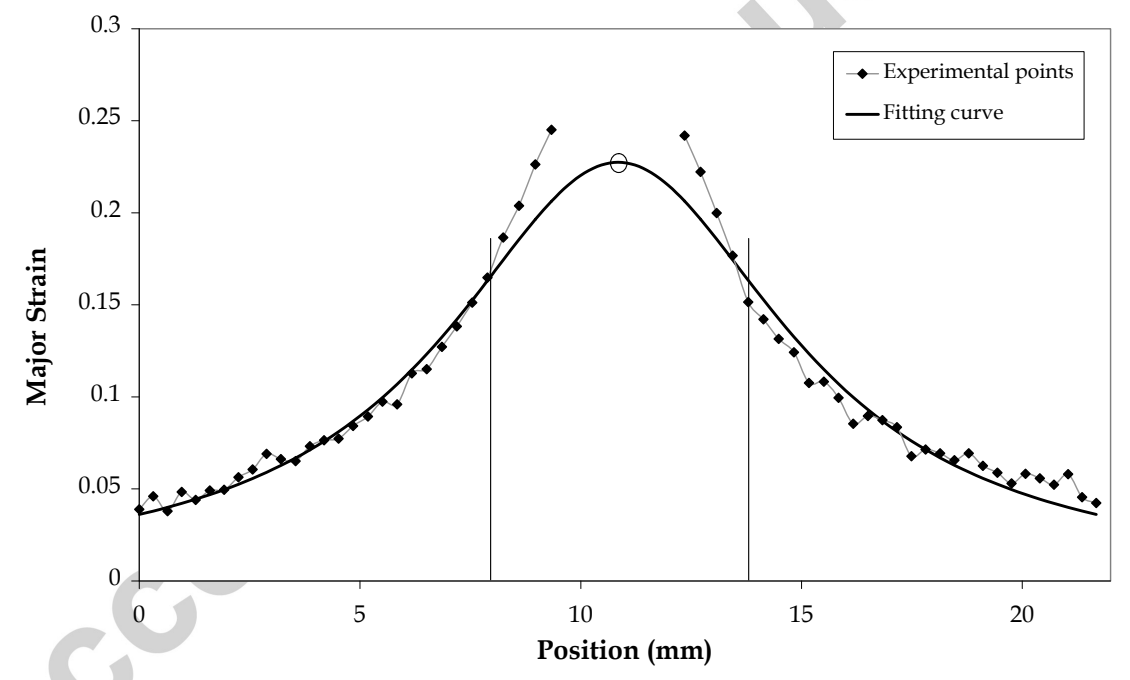

Figure 5: Curve fit of the major strain distribution along section 2 (Fig. 4(a)).

Using the position-dependent method, figure 6 shows the experimental forming limit points for an aluminum alloy 5086. For each specimen, the 
strain path is also superimposed in figure 6. As expected, all the strain paths are quasi-linear for constant speed ratios $S 2 / S 1$. Besides, the data scatter is reasonable for the whole forming limit diagram. For the left hand side of the forming limit diagram, less experimental data are presented because the forming limit points are commonly located along a quasi straight line, so more experiments were led in the critical zone of plane strain.

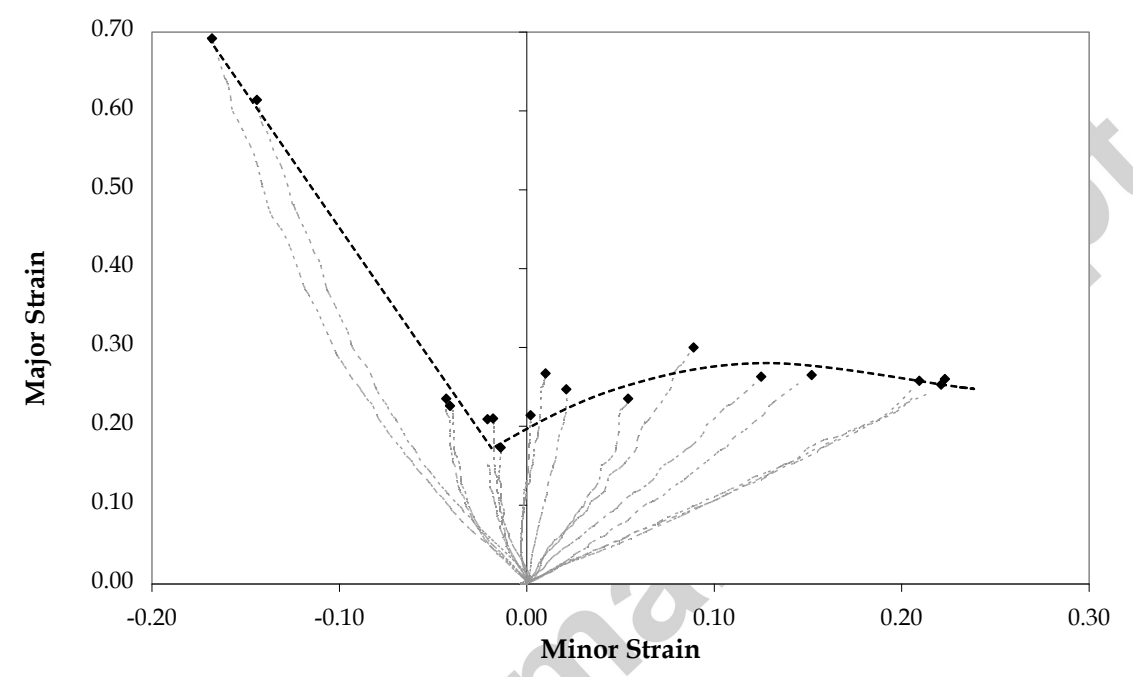

Figure 6: Experimental forming limit points with the position-dependent method.

For comparison, forming limit points obtained with the three methods (position-dependent method, critical ratio method and time-dependent method) are shown in figure 7 . For the critical ratio method, a critical ratio value of 7 is chosen in order to correlate with the results from the positiondependent method. The calibration method is based on the specific points close to plane strain conditions which are frequently critical for the forming of industrial parts. Due to the data scatter inherent to the onset of plastic instabilities, it would not be precise to calibrate the critical ratio with 
only one experimental point. The calibration is made by considering the experimental points in the forming limit diagram for which the minor strain is upper than $-5 \%$ and lower than $5 \%$. An average major strain is calculated in this zone ( 8 experimental points) and is equal to $22.2 \%$ for the position-dependent and the critical-ratio method with a critical ratio value of 7 . Nevertheless, the results presented in figure 7 show that the FLCs from position-dependent method and critical ratio method are very close for all the strain states. This very easy to use method is perfectible but the value of 7, already defined by some authors for the classical M-K model [27], gives us accurate forming limit points. Since the strain fields are heterogeneous in the cruciform shape, the critical value of the strain increment ratio depends on the position of the reference zone (zone 2 in Fig. 4(b)). The choice of the time increment to calculate the strain increment has also an influence on the value of the critical ratio. If a short time increment is chosen, the strain increment ratio will increase more quickly and in this case, forming limit values are less sensitive to the choice of the value of the critical ratio. To avoid some fluctuations associated with the accuracy of the experimental strain measurement, a time increment of $0.5 \mathrm{~s}$ was chosen. To evaluate the influence of the value of the critical ratio, a value of 10 will move the forming points upward and the increase of major strains will be close to $30 \%$. The time-dependent method proposed by Merklein et al. in [26] has been applied. Figure 7 shows that the results from the position-dependent method and from the critical ratio method are very close and a higher data scatter is noticed for the time-dependent method. For AA5086, the natural scattering due to multiple derivatives is certainly emphasized by plastic instabilities, 
like Portevin-Le Chatellier effects. For a given method to detect the onset of necking, the correlation between experimental results from the presented biaxial tensile test and from the conventional Marciniak test is very good [2].

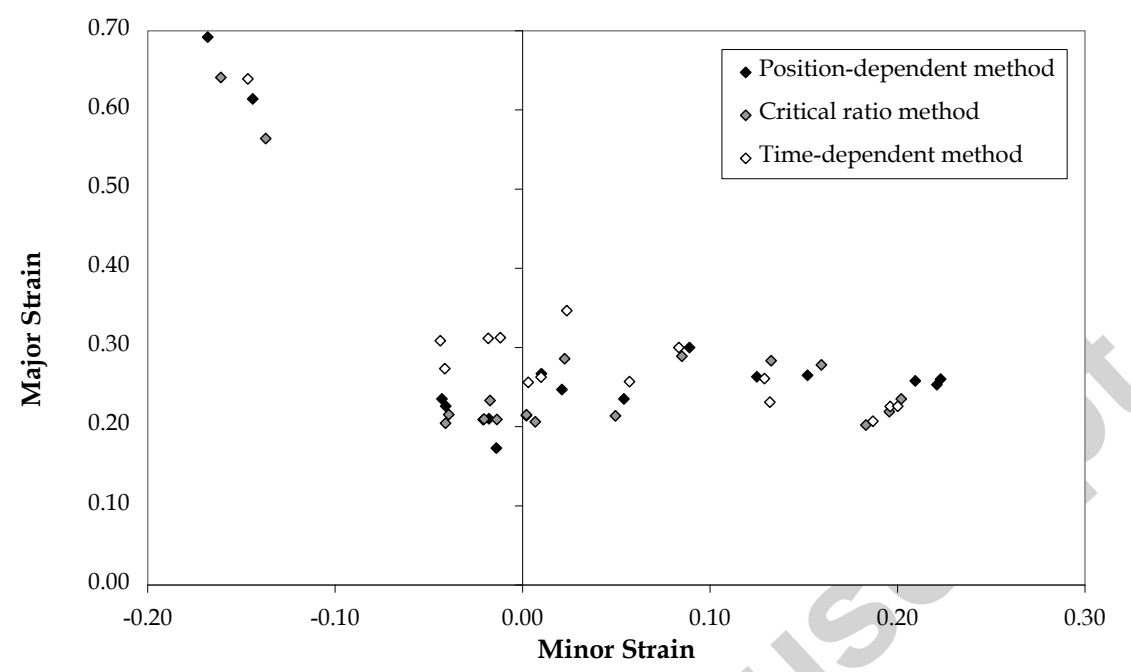

Figure 7: Comparison of the three methods for the detection of forming limit points.

\subsection{Non-linear loadings}

It appears that the position-dependent method is relatively efficient for linear loadings and the same method is now applied for non-linear loadings. To illustrate the potential of the in-plane biaxial tensile test to study the effects of strain path changes on formability, a prestrain in uniaxial tension is first applied along the rolling direction (Step 1 in Fig. 8). This first step is then followed by a deformation in equibiaxial tension (Step 2 in Fig. 8). Different displacements from $1 \mathrm{~mm}$ to $3 \mathrm{~mm}$ have been tested, corresponding respectively to levels of prestrain from $5 \%$ to $19 \%$. 


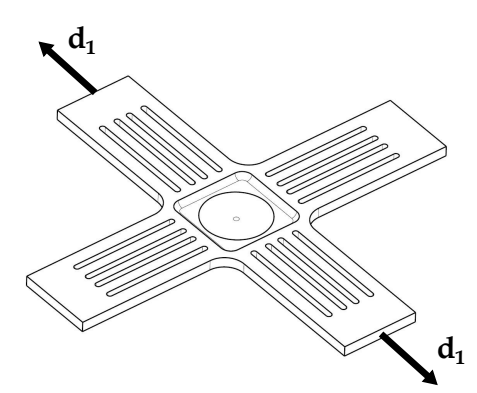

STEP 1 : Prestrain in uniaxial tension

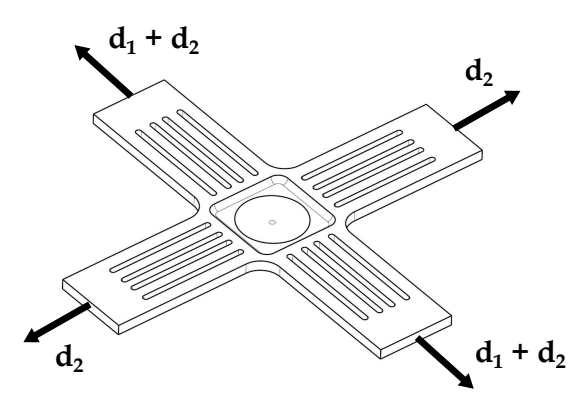

STEP 2 : Equibiaxial tension

Figure 8: Prestrain in uniaxial tension before deformation in equibiaxial tension.

Figure 9 depicts the forming limit points with the different levels of prestrain. The strain paths are also superimposed for all the tested specimens. As expected, the transition from step 1 to step 2 corresponds to an abrupt strain path change. As already observed for linear loadings, scattering of forming limit points is rather low. In the right-hand side of the forming limit diagram, a small increase of formability is observed with the level of prestrain (step 1 - displacements from $1 \mathrm{~mm}$ to $2.5 \mathrm{~mm}$ (prestrains from $5 \%$ to $13 \%$ )). By contrast, the formability strongly decreases for a prestrain corresponding to a displacement of $3 \mathrm{~mm}$ (prestrain of 19\%). For this prestrain, step 2 is immediately followed by a necking and then a rupture of the specimen. This phenomenon is very reproducible since three specimens have been tested and give exactly the same results.

For comparison, figure 10 summarizes the experimental forming limit points for the linear and non-linear loadings. Clearly, abrupt changes in strain path can produce significant changes in the forming limit strains. For small prestrains in uniaxial tension along the rolling direction (major strain 


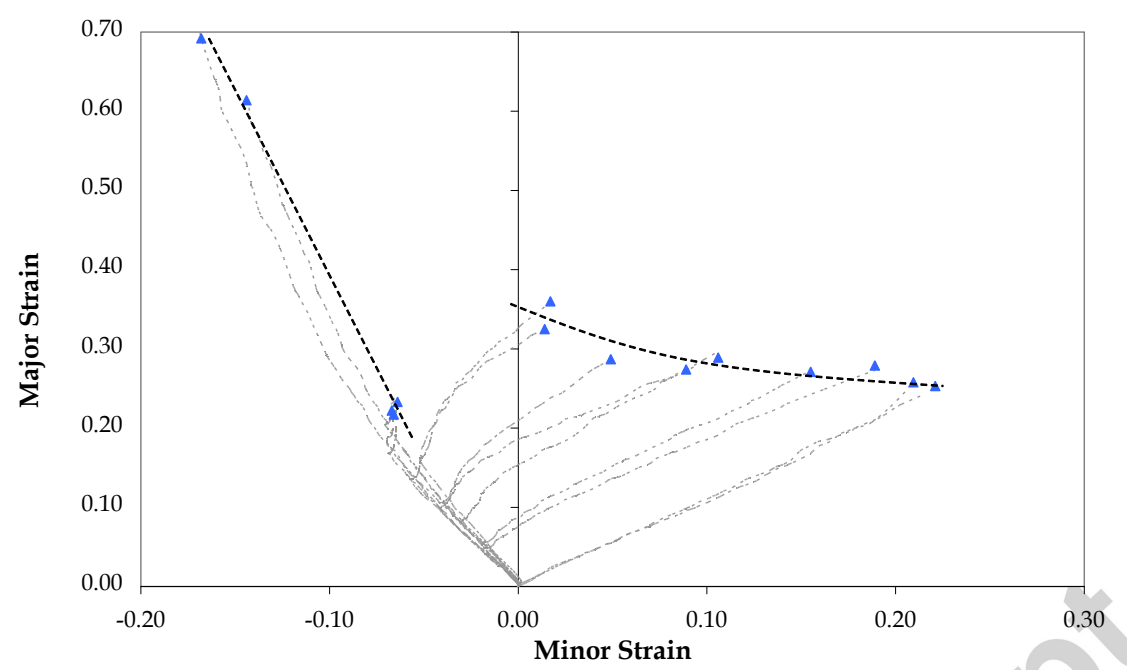

Figure 9: Experimental forming limit points with different levels of prestrain in uniaxial tension.

below 15\%), the forming limit points are shifted upward and then the sheet formability is improved. This result is in accordance with the predictions from some authors [13]. But when the major prestrain in uniaxial tension is higher than $15 \%$, a premature necking develops and the material formability is strongly reduced. The same conclusions were given by the analytical study of Kuroda and Tvergaard [11] for the same non linear path, without unloading. An abrupt jump of forming limit curve were observed but this premature necking was not validated by experiments. As shown in figure 10, a discontinuous forming behaviour with prestrain level is observed and the aim of the following section is to see if this very interesting result can be predicted by a finite element modeling of the cruciform shape. 


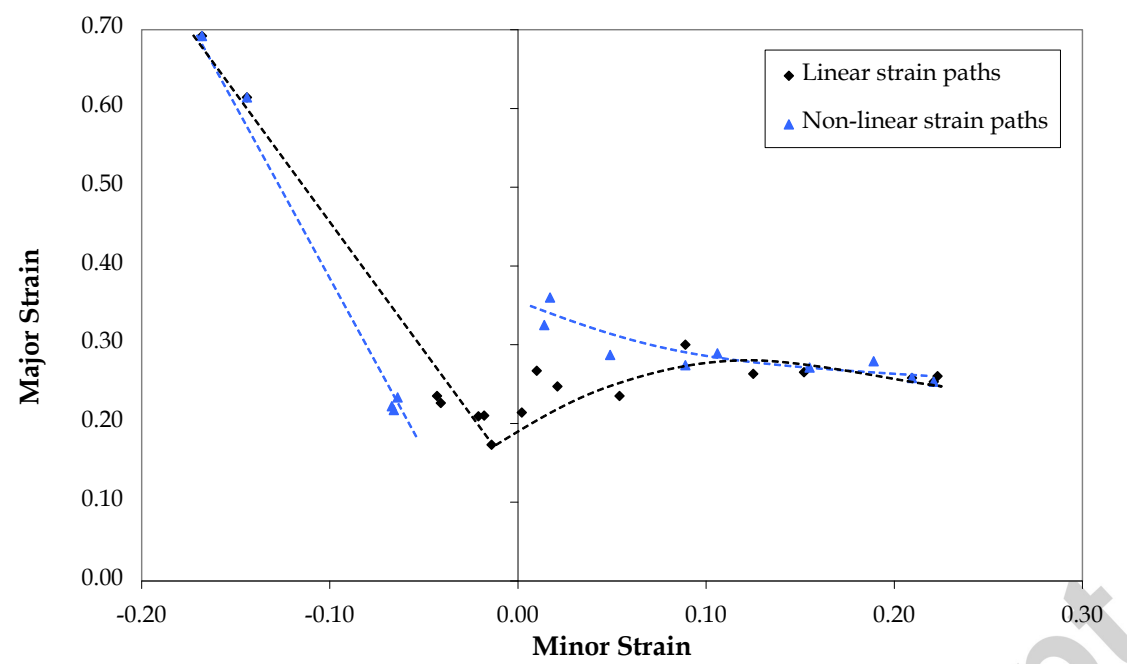

Figure 10: Comparison of forming limit points with linear and non-linear strain paths.

\section{Prediction of strain path changes}

\subsection{Numerical model}

A predictive model for forming limit curves has been built by modeling the cruciform specimen shape (Figure 1) with the finite element method. Due to the symmetrical properties of the specimen, only one-quarter is modeled (Figure 11). Tetrahedral elements are used and a refined mesh is assumed where strain localization may appear (central zone, fillet, grooves).

The elastic part is described by Hooke's model (Young's modulus of $67290 \mathrm{MPa}$ and Poisson's ratio of 0.3). To model the plastic behaviour of the material, the hardening is introduced thanks to a saturation law based on the Voce's formulation (Eq. 1) :

$$
\bar{\sigma}=\bar{\sigma}_{0}+\mathrm{Q} \sqrt{1-\mathrm{e}^{-\mathrm{B} \bar{\varepsilon}}}
$$




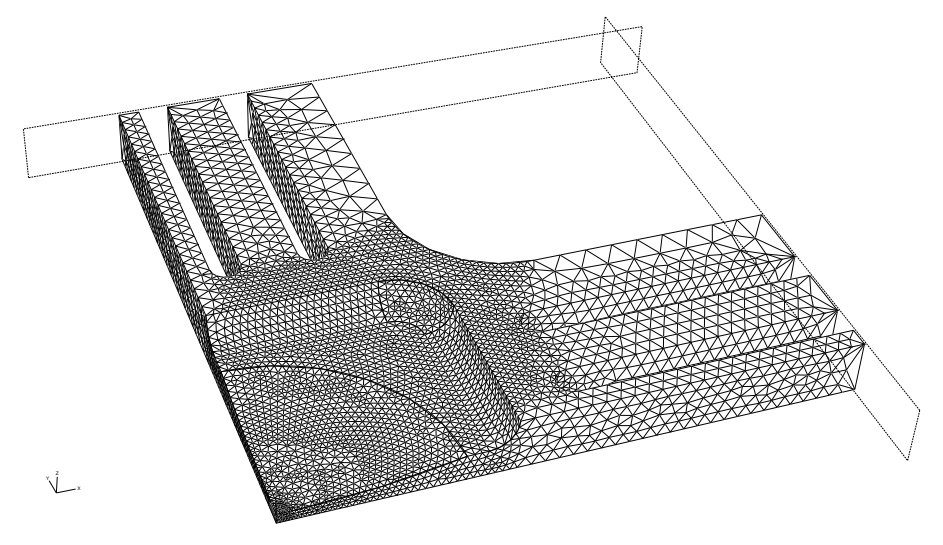

Figure 11: Mesh of the cruciform specimen.

where $\bar{\sigma}$ and $\bar{\varepsilon}$ are respectively the equivalent stress and the equivalent plastic strain. Constitutive model parameters are constants identified from a mono-axial test on a constant section AA5086 specimen (Tab. 1). The hardening law is implemented in the finite element code ABAQUS by means of the Fortran subroutine UHARD.

\begin{tabular}{ccc}
\hline $\bar{\sigma}_{0}(M P a)$ & $Q(M P a)$ & $B$ \\
\hline 130.2 & 300.4 & 3.94 \\
\hline
\end{tabular}

Table 1: Constitutive model parameters for the Voce's law.

The choice of the yield criterion for this predictive model is also discussed hereafter. The isotropic Mises's criterion is compared with the classical anisotropic Hill48 yield criterion. The anisotropy of this alloy is relatively low in the plane of the sheet and does not present abnormal behaviour, so Hill48 yield criterion can give an acceptable description of this anisotropy even if a criterion with two linear transformation tensors (Bron and Besson) was shown to be better for this material [28]. For Hill48 criterion, the equiv- 
alent stress $\bar{\sigma}$ is expressed by a quadratic function of the following type :

$$
2 \bar{\sigma}^{2}=F\left(\sigma_{y}-\sigma_{z}\right)^{2}+G\left(\sigma_{z}-\sigma_{x}\right)^{2}+H\left(\sigma_{x}-\sigma_{y}\right)^{2}+2 L \sigma_{y z}^{2}+2 M \sigma_{z x}^{2}+2 N \sigma_{x y}^{2}
$$

where $F, G, H, L, M$ and $N$ are constants specific to the state of anisotropy of the material. The direction $x$ is the rolling direction, $y$ the transverse direction and $z$ the normal direction. The parameters of the Hillus criterion have been identified from Lankford's coefficients $\left(r_{0}, r_{45}\right.$ and $\left.r_{90}\right)$ and are given in table 2 .

\begin{tabular}{ccccccccc}
\hline$r_{0}$ & $r_{45}$ & $r_{90}$ & $F$ & $G$ & $H$ & $L$ & $M$ & $N$ \\
\hline 0.57 & 0.52 & 0.62 & 0.7 & 0.637 & 0.363 & 1.5 & 1.5 & 1.63 \\
\hline
\end{tabular}

Table 2: Lankford's coefficients and Hill48 yield parameters.

Different speed ratios must be imposed on the two perpendicular directions of the cross specimen in order to cover the whole forming limit diagram. Since rupture criterion and damage law are not introduced in the finite element model of the cruciform shape, it is rather difficult to apply the experimental position-dependent method. Nevertheless, the critical ratio method with a critical value of 7 has been proved to be efficient and is very easy to use numerically. Then the critical ratio method has been applied to detect strain localization and identify the numerical forming limit curves. Figure 12 gives a comparison between predictive and experimental forming limit points for linear loadings and shows the impact of yield criterion on the prediction of FLCs.

It appears in figure 12 that the FLC predictions in the right-hand side of the FLD are very conservative for the isotropic yield criterion $(V M)$ whereas 


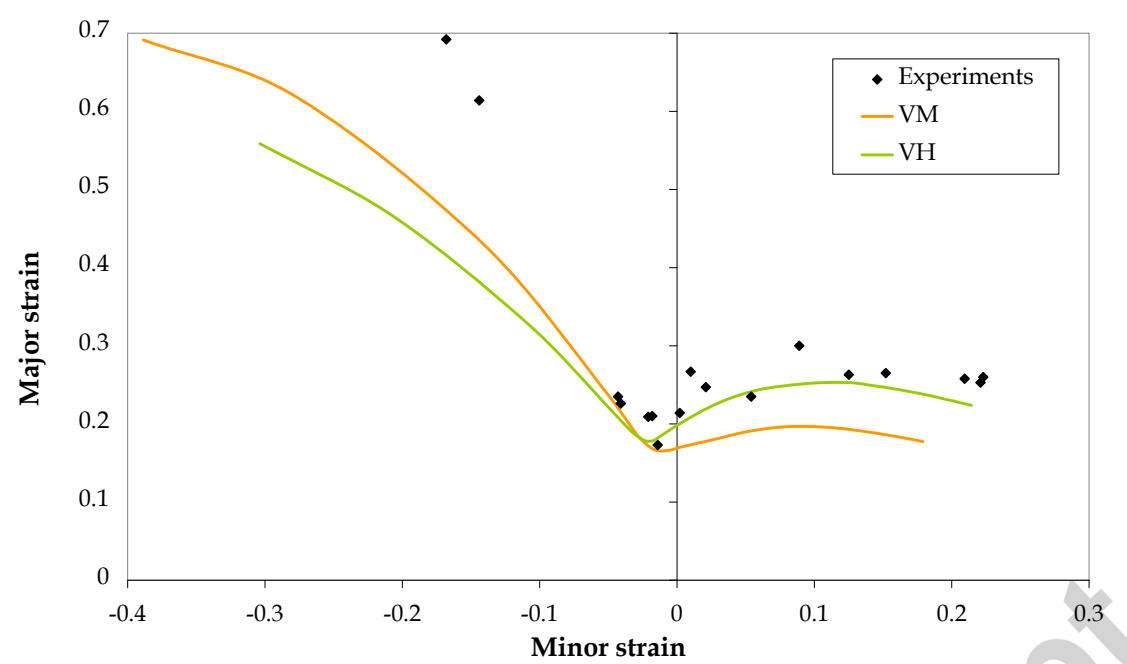

Figure 12: Comparison between predictive (Voce's hardening + Mises (VM), Voce's hardening + Hill48 $(\mathrm{VH}))$ and experimental forming limit points for linear paths.

a good correlation is found for the anisotropic Hill48 criterion $(V H)$. For the left-hand side, the two formulations underestimate the formability. By means of these numerical predictions with two different elastoplastic behaviours, it is demonstrated that the material modeling greatly influences the level and shape of predictive FLCs. But the predictive model with Hill48 criterion gives good predictions, especially for plane strain path which is generally critical in industrial processes. Moreover, unlike the classical M-K model, the calibrating step of an initial geometrical imperfection is not necessary.

\subsection{Comparison between experimental and numerical non-linear loadings}

Figure 13 compares predictive and experimental strain paths for linear and non-linear loadings. A good correlation is found with experiments and Hill48 model gives also better predictions. After the strain path change, the yield criterion noticeably influences the slope of the second strain path. A 
very small elastic unloading is observed which is certainly due to the quick change of stress point along the yield surface, after the abrupt strain path change.

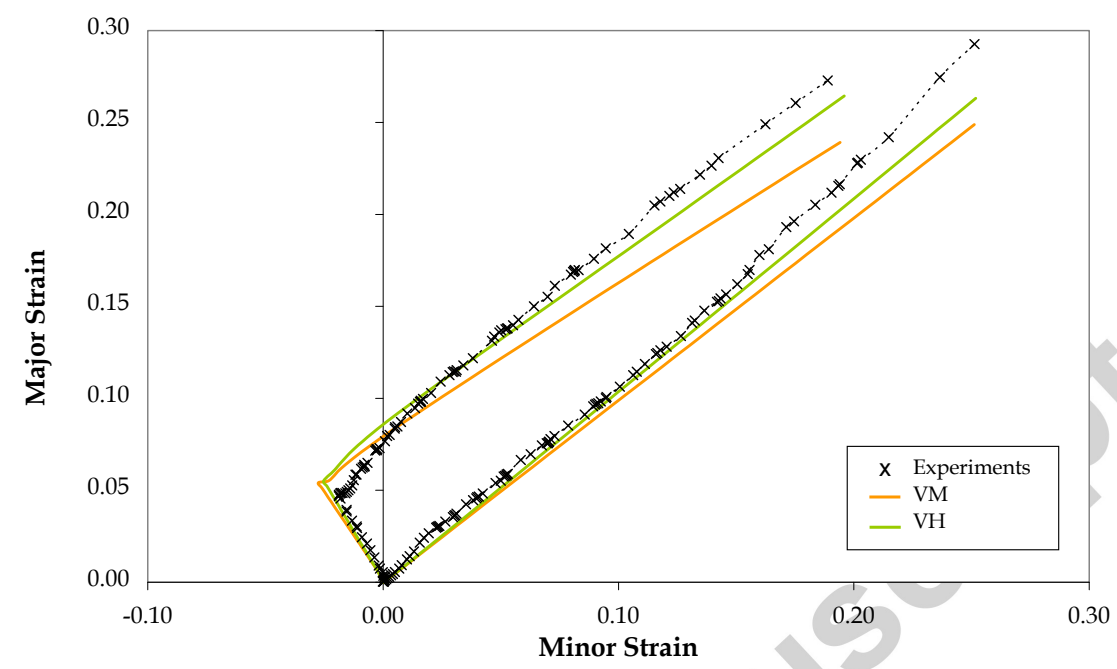

Figure 13: Comparison between predictive and experimental strain paths for linear and non-linear loadings.

Finally, predictive FLCs for the experimentally tested non-linear paths are given for the two yield criteria (Fig. 14). It is noteworthy that the calculated FLCs give the same tendencies than experimental results. In the right-hand side of the FLD, for small values of prestrain, an increase of formability is clearly observed. But for a prestrain higher than 15\%, a sudden change in formability appears which leads to a formability drop. Experimental and calculated forming limit points are rather close and the influence of yield criterion is emphasized with non-linear loadings.

In order to provide a better understanding of the abrupt change in formability with prestrain, the time evolution of equivalent strain increment ratio 


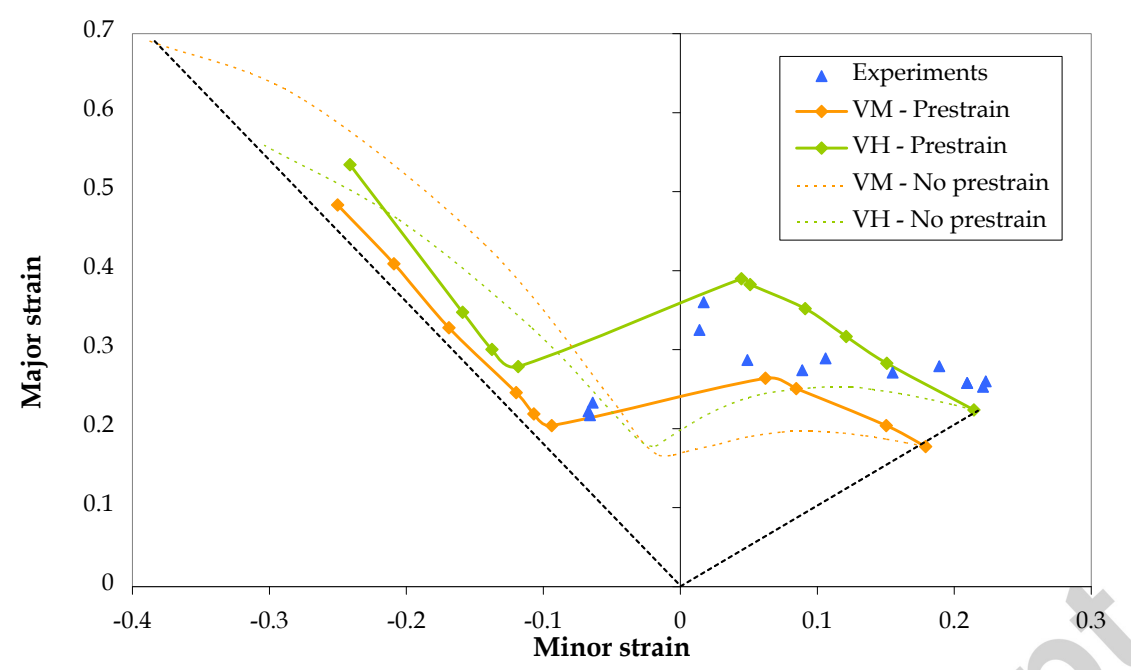

Figure 14: Comparison between predictive and experimental forming limit points for nonlinear paths.

between the two reference zones is given in figure 15. For all the prestrains, the strain path change (after a time period of 1.5 ) is followed by a systematic increase of the strain ratio which indicates a "pseudolocalization" at the center of the specimen. When the prestrain is small, this pseudolocalization is stabilized after a time period of 2.5 and the increment ratio decreases until a new increase associated with the onset of necking for a time period close to 4 . For a prestrain of $19 \%$ corresponding to a displacement of $3 \mathrm{~mm}$, the evolution of equivalent strain ratio is quite different. The increase is more abrupt and the strain ratio exceeds the critical value of 7 . Following the critical ratio criterion, this first plastic instability will not be stabilized which will cause the sudden rupture of the specimen. Experimentally, a premature necking and rupture is also observed for the same prestrain. This good correlation tends to confirm that the critical value of 7 , calibrated for linear strain paths, 
is still consistent for non-linear strain paths. The finite element modeling of the cruciform shape, associated with the critical ratio criterion, can be an efficient tool to predict pseudolocalization and premature necking. This last point must be confirmed with additional non-linear strain paths.

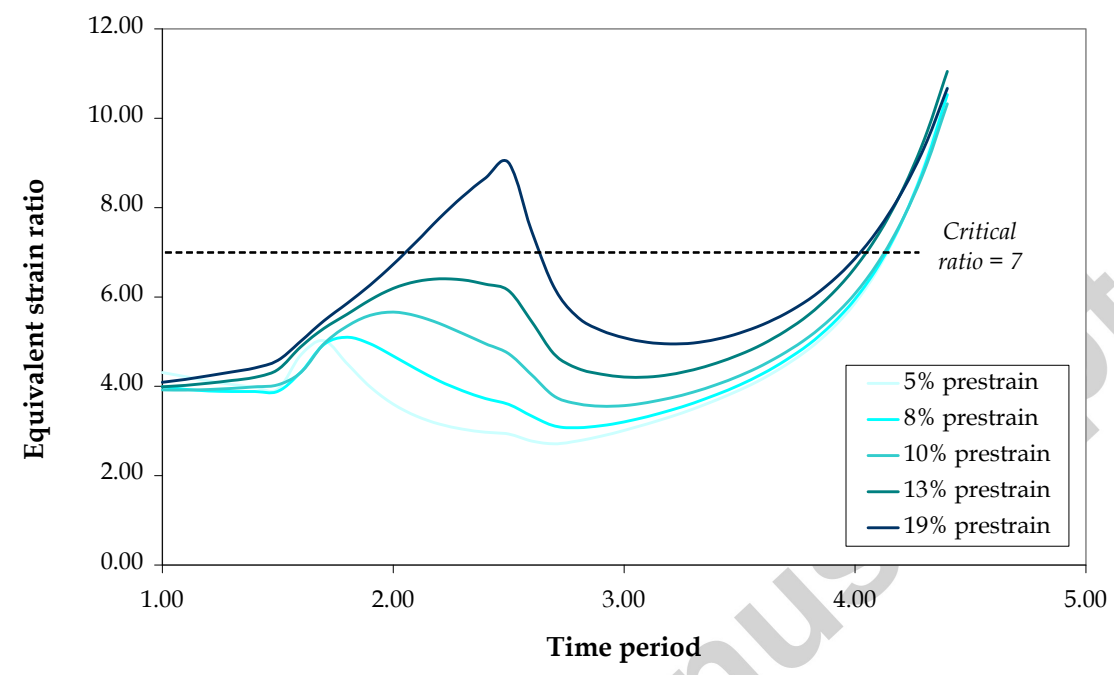

Figure 15: Equivalent strain increment ratio for different prestrains.

\section{Conclusions}

In actual forming processes, complex loading paths are generally observed. Due to the influence of loading procedure on the forming limits of the material, the classical two-steps procedure with unloading is not appropriate to characterize the influence of strain path changes on formability. An innovative one-step procedure has been successfully performed to characterize and predict sheet formability with a cruciform shape, without unloading.

For the tested aluminum alloy, abrupt changes in strain path can produce significant changes in the forming limit strains. The level of prestrain 
can either improve or reduce formability. A high prestrain in uniaxial tension (close to 20\%) leads to a premature failure of the specimen when it is followed by equibiaxial tension. The use of a finite element model of the cruciform shape to predict forming limits gives the same tendencies. For a high prestrain, a strain localization is detected by the critical ratio method and develops in the center of the specimen, this localization is not stabilized after the abrupt change of strain path. As it was already shown in previous studies, the choice of the material modeling greatly influences the level and shape of predictive FLCs.

Strain path is controlled by actuator displacements in the two main directions of the cruciform specimen and effects of strain path changes can be investigated without any restriction about the type of non-linear path, like multiple step or continuous strain path changes. Moreover, with the one-step procedure, operating environment factors like temperature or strain rate can be easily included in the study in order to supply reliable forming limits for industrial applications.

\section{References}

[1] X. Chu, L. Leotoing, D. Guines, and E. Ragneau. Temperature and strain rate influence on AA5086 forming limit curves: Experimental results and discussion on the validity of the M-K model. International Journal of Mechanical Sciences, 78:27-34, 2014.

[2] L. Leotoing, D. Guines, I. Zidane, and E. Ragneau. Cruciform shape benefits for experimental and numerical evaluation of sheet metal formability. Journal of Materials Processing Technology, 213:856-863, 2013. 
[3] International Standard ISO16842. Metallic materials - sheet and strip - biaxial tensile testing method using a cruciform test piece. Technical report, ISO, 2014.

[4] T. Kuwabara, S. Ikeda, and K. Kuroda. Measurement and analysis of differential work hardening in cold-rolled steel sheet under biaxial tension. Journal of Materials Processing Technology, 80-81:517-523, 1998.

[5] W. Muller and K. Pohlandt. New experiments for determining yield loci of sheet metal. Journal of Materials Processing Technology, 60:643-648, 1996.

[6] D.E. Green, K.W. Neale, Makinde A. MacEwen, S.R., and R. Perrin. Experimental investigation of the biaxial behaviour of an aluminium sheet. International Journal of Plasticity, 20:1677-1706, 2004.

[7] Y. Yu, M. Wan, X-D Wu, and X-B Zhou. Design of a cruciform biaxial tensile specimen for limit strain analysis by FEM. Journal of Materials Processing Technology, 123:67-70, 2002.

[8] I. Zidane, D. Guines, L. Leotoing, and E. Ragneau. Development of an in-plane biaxial test for forming limit curve (FLC) characterization of metallic sheets. Measurement Science and Technology, 21:1-11, 2010.

[9] A. Barata Da Rocha, F. Barlat, and J.M. Jalinier. Prediction of the forming limit diagrams of anisotropic sheets in linear and non-linear loading. Materials Science and Engineering, 68:151-164, 1984.

[10] K. Yoshida, T. Kuwabara, and M. Kuroda. Path-dependence of the 
forming limit stresses in a sheet metal. International Journal of Plasticity, 23:361-384, 2007.

[11] M. Kuroda and V. Tvergaard. Effect of strain path change on limits to ductility of anisotropic metal sheets. International Journal of Mechanical Sciences, 42:867-887, 2000.

[12] S. Hiwatashi, A. Van Bael, P. Van Houtte, and C. Teodosiu. Prediction of forming limit strains under strain-path changes : application of an anisotropic model based on texture and dislocation structure. International Journal of Plasticity, 14:647-669, 1998.

[13] C.L. Chow, L.G. Yu, W.H. Tai, and M.Y. Demeri. Prediction of forming limit diagrams for AL6111-t4 under non-proportional loading. International Journal of Mechanical Sciences, 43:471-486, 2001.

[14] R. Arrieux, C. Bedrin, and M. Boivin. Determination of an intrinsic forming limit stress diagram for isotropic sheets. In Proceedings of the 12th IDDRG congress, pages 61-71, Santa Margherita, 1982.

[15] T. B. Stoughton. A general forming limit criterion for sheet metal forming. International Journal of Mechanical Sciences, 42:1-27, 2000.

[16] T.B. Stoughton and J.W. Yoon. Sheet metal formability analysis for anisotropic materials under non-proportional loading. International Journal of Mechanical Sciences, 47:1972-2002, 2005.

[17] M.C. Butuc, J.J. Gracio, and A. Barata Da Rocha. An experimental and theoretical analysis on the application of stress-based forming limit criterion. International Journal of Mechanical Sciences, 48:414-429, 2006. 
[18] M. Butuc, F. Barlat, J. Gracio, and G. Vincze. A theoretical study of the effect of the double strain path change on the forming limits of metal sheet. Key Engineering Materials, 554-557:127-138, 2013.

[19] M. Nurcheshmeh and D. E. Green. The effect of normal stress on the formability of sheet metals under non-proportional loading. International Journal of Mechanical Sciences, 82:131-139, 2014.

[20] R. Uppaluri, N. Venkata Reddy, and P.M. Dixit. An analytical approach for the prediction of forming limit curves subjected to combined strain paths. International Journal of Mechanical Sciences, 53:365-373, 2011.

[21] A. Graf and W. Hosford. The influence of strain-path changes on forming limit diagrams of al 6111 t4. International Journal of Mechanical Science, 36:897-910, 1994.

[22] J. Cao, H. Yao, A. Karafillis, and M.C. Boyce. Prediction of localized thinning in sheet metal using a general anisotropic yield criterion. International Journal of Plasticity, 16:1105-1129, 2000.

[23] W. Volk, H. Hoffmann, J. Suh, and J. Kim. Failure prediction for nonlinear strain paths in sheet metal forming. CIRP Annals - Manufacturing Technology, 61:259-262, 2012.

[24] A. Hannon and P. Tiernan. A review of planar biaxial tensile test systems for sheet metal. Journal of Materials Processing Technology, 198:18, 2008.

[25] A. Petek, T. Pepelnjak, and K. Kuzman. An improved method for 
determining forming limit diagram in the digital environment. Journal of Mechanical Engineering, 51:330-345, 2005.

[26] M. Merklein, A. Kuppert, and M. Geiger. Time dependent determination of forming limit diagrams. CIRP Annals - Manufacturing Technology, 59:295-298, 2010.

[27] D. Banabic, S. Comsa, P. Jurco, G. Cosovici, L. Paraianu, and D. Julean. FLD theoretical model using a new anisotropic yield criterion. Journal of Material Processing Technology, 157-158:23-27, 2004.

[28] S. Zhang, L. Leotoing, D. Guines, S. Thuillier, and S. Zang. Calibration of anisotropic yield criterion with conventional tests or biaxial test. International Journal of Mechanical Sciences, 85:142-151, 2014. 